\title{
İntörn Öğrencilerin Hasta Güvenliği Tutum ve Kültürlerinin Tıbbi Hata Durumlarına Etkisi
}

\author{
Gülbahtiyar Demirel'®i, Özlem Akgün²®, Adem Doğaner ${ }^{3}$
}

${ }^{1}$ Cumhuriyet Üniversitesi, Sağlık Bilimleri Fakültesi, Ebelik Bölümü, Sivas, Türkiye

²Bozok Üniversitesi, Akdağmadeni Sağlık Yüksekokulu, İş Sağlığı ve Güvenliği Bölümü, Yozgat, Türkiye ${ }^{3}$ Kahramanmaraş Sütçü İmam Üniversitesi Tıp Fakültesi, Biyoistatistik ve Tıbbi Bilişim Bölümü, Kahramanmaraş, Türkiye

Gülbahtiyar Demirel, Doç. Dr. Özlem Akgün, Öğr. Gör. Adem Doğaner, Dr. Öğr. Üyesi

İletişim:

Doç. Dr. Gülbahtiyar Demirel Cumhuriyet Üniversitesi, Sağlık Bilimleri Fakültesi, Ebelik Bölümü, Sivas, Türkiye Tel: +903462191010

E-Posta: gulbahtiyar_doganer@hotmail.com
ÖZET

Amaç: Bu çalışma sağlık bilimleri alanındaki intörn öğrencilerin hasta güvenliği tutum ve kültürlerinin tıbbi hata durumlarına etkisini belirlemek amacıyla planlanmıştır.

Gereç ve Yöntem: Tanımlayııı ve kesitsel olarak gerçekleştirilen çalışmanın örneklemini Cumhuriyet Üniversitesi kampüsünde 2017-2018 eğitim-öğretim döneminde sağlık bilimleri alanında öğrenim gören son sınıf (intörn) öğrencileri ( $n=624$ kişi; Hemşirelik, Ebelik ve Sağlık Yönetimi Bölümü, Diş Hekimliği, Tip ve Eczacılık Fakültesi) oluşturmuştur. Veriler "Öğrenci Tanılama Formu", “Hasta Güvenliği Kültürü Ölçeği (HGKÖ)” ve “Hasta Güvenliği Tutum Ölçeği (HGTÖ)” ile toplanmıştır. İstatistiksel değerlendirmede median (min-max), yüzdelik dağılım ve Kruskal Wallis testi kullanılmıştır.

Bulgular: Araştırma yer alan son sınıf öğrencilerinin; \%24'ü tıp fakültesi, \%11,1'i diş hekimliği fakültesi, \%35,6'sı hemşirelik bölümü, \%11,4'ü ebelik bölümü, \%15,2'si sağlık yönetimi bölümü, \%2,7'si eczacılık fakültesindendir. Hasta güvenliği açısından öğrencilerin en sık yaptığı tıbbi hataların başında ilaç hataları $(\% 50,8)$ ve iletişim sorunlarından kaynaklı hatalar $(\% 24,4)$ gelmektedir. öğrencilerin yaptığı ilaç hatalarının başında ise yanlış ilacın verilmesi $(\% 16,7)$ ve yanlış doz $(\% 14,8)$ ile verilmesi gelmektedir. Öğrencilerin hasta güvenliğine ilişkin kültür $(2,88(1,00-3,90))$ ve tutumları $(160(81,00-193,00))$ olumlu yönde orta düzeyin üzerindedir. Düşmelere bağlı hata ve ilaç hataları gerçekleştirenler daha olumsuz hasta güvenliği kültür ölçeği puanına sahiptir. Ölçek puanları bakımından ilaçla yapılan hata türleri arasında en olumsuz seyri yanlış ilacı verenler izlemiş̧ir. Eczacılık ve tıp intörn öğrencileri arasında hasta güvenliğine ilişkin tutum diğer bölümlere göre daha olumsuzdur $(p<0,05)$.

Sonuç: Öğrencilerin hasta güvenliği kültür ve tutumları istendik düzeyde değildir ve bu durum hata yapma sıklı̆ııı veya olasılığını artırmaktadır.

Anahtar sözcükler: Hasta güvenliği, öğrenci, tıbbi hata

\section{A THE EFFECT OF PATIENT SAFETY ATTITUDES AND CULTURES ON MEDICAL ERRORS OF INTERN STUDENTS}

\section{ABSTRACT}

Objective: This study was conducted to determine the effect of patient safety attitudes and cultures on medical errors in intern students studying health sciences ( $\mathrm{OR}$ : studying in health sciences faculty).

Materials and Methods: The sample of this descriptive and cross-sectional study composed of intern students ( $n=624$ people; Nursing, Midwifery and Health Management Department, Dentistry, Medicine and Faculty of Pharmacy) studying health sciences during the 2017-2018 academic year at Cumhuriyet University. The data were collected by the "Student Description Form", "Patient Safety Culture Scale (PSCS)" and "The Safety Attitudes Questionnaire (SAQ)". Median (min-max), percentage distribution and Kruskal-Wallis test were used for statistical evaluation.

Results: of senior students in the study, $24 \%$ of them are from medical faculty, $11.1 \%$ from dentistry faculty, $35.6 \%$ from the department of nursing, $11.4 \%$ from the department of midwifery, $15.2 \%$ from the department of health management and $2.7 \%$ of them are from the faculty of pharmacy. In terms of patient safety, the most common medical errors made by students are drug errors $(50.8 \%)$ and communication errors $(24.4 \%)$. The most common drug errors made by the students are giving the wrong medication (16.7\%) and giving the wrong dose of medication (14.8\%). The culture (2.88 (1.00-3.90)) and attitudes (160 (81.00-193.00)) of students towards patient safety are positively above the average. Those who perform fall-related errors and drug errors have a more negative patient safety culture score. In terms of scale scores, the most negative course was performed by the ones giving the wrong drugs to patients among the error types made with the drug. The attitude towards patient safety between intern pharmacy and medical students is more negative than the other departments $(p<0.05)$.

Conclusion: It has been determined that the patient safety culture and attitudes of students are not at the desired level and this increases the frequency or probability of the occurring medical errors.

Keywords: Patient safety, student, medical error 
ünümüzde sağlık hizmetlerinin önemli konularından birisi hasta güvenliğidir (1-3). Sağlıklı/hasta bireyin güvenli bir ortamda sağlık hizmeti alması temel hasta haklarından biridir (4). Hasta güvenliği, kaliteli ve nitelikli sağlık hizmetlerinin birincil ve vazgeçilmez koşulu olup, sağlık bakım hizmetlerinin kişilere vereceği zararı önlemek amacıyla sağlık kuruluşları ve kuruluştaki çalışanlar tarafından sağlık bakımının her aşamasında tıbbi hatalardan kaçınılması ve alınan önlemlerin tamamıdır $(2,4,5)$.

Tıbbi hatalar tüm sağlık çalışanları için önemli bir konudur (6). Sağlık çalışanları hasta güvenliği kapsamında yer alan ilaç hatalarının, cerrahiye ilişkin hataların, hasta düşmelerinin, hastane enfeksiyonlarının ve bası yaralarının önlenmesi ve malzeme güvenliğinin sağlanmasında önemli sorumluluklar üstlenmektedirler $(2,7)$. Hasta güvenliği açısından sağlık hizmetlerinde en sık karşılaşılan hataların başında; ilaç hataları, hastane enfeksiyonları, düşmeler, yetersiz izlem, iletişim sorunları ve malzeme kullanımına bağlı hatalar gelmektedir (8).

Hasta güvenliğini sağlamanın temeli, hasta güvenliği kültürünün oluşturulmasından geçmektedir (9). Güvenlik kültürünün sağlanmasında sağlık hizmeti sunanların algıları ve tutumlarının belirlenmesi önemlidir (10). Sağlık kurumlarında yaşanan tıbbi hatalar bireysel sağlık harcamalarına ve ülke ekonomisine ciddi bir yük getirmektedir (11). Dünya Sağlık Örgütü'ne göre her 10 hastadan biri tıbbi hatalar nedeniyle ciddi şekilde zarar görmektedir (12). Sağlık profesyonellerinin neden olduğu tıbbi hatalar, önlenebilir nitelikte hatalardır, eğitimlerle etkin ve güçlü bir hasta güvenlik kültürü oluşturularak hasta güvenliği sağlanabilir (13). Tıbbi hataların başlıca nedenleri; iletişim problemleri, yetersiz bilgi akışı, standart bakım, politika ve prosedürleri uygulamayan sağlık profesyoneli, hasta ile ilgili sorunlar (hasta kimliğinin yanlış tespit edilmesi, hasta hakkında yetersiz bilgi sahibi olma, yetersiz hasta eğitimi), kurumun çalışanlarına bilgi ve eğitim aktarımında yeterli olmaması, personel yetersizliği, iş yükünün fazla olması, kurumlarda teknik yetersizliklerin olması ve yetersiz politika, prosedürler olarak sıralanmaktadır (14).

Sağlık sisteminde sağlık bilimi alanındaki öğrencilere eğitim süresince kliniklerde uygulama fırsatı sağlanır (5). Öğrencinin sağlıklı/hasta bireye herhangi bir uygulama yapması hem öğrenci hem de uygulama yapılacak birey için büyük bir stres kaynağıdır. Uygulama alanında hasta ile karşılaşma, hastaya herhangi bir uygulama yapma öğrencilerde anksiyete ve korkuya neden olabilmektedir $(15,16)$. Bu durum ise öğrencilerin tıbbi hata yapmasına yol açabilmektedir (16). Hasta güvenliği kültürünün yerleştirilip geliştirilmesi, aynı zamanda tüm sağlık personeli ve sağlık personel adayları (öğrencileri) tarafından benimsenmesi ile tıbbi hata ve riskler en az sayıya indirilebilir (2). Bu nedenle çalışma sağlık bilimleri alanındaki intörn öğrencilerin hasta güvenliği tutum ve kültürlerinin tıbbi hata durumlarına etkisini belirlemek amacıyla planlanmıştır.

\section{Gereç ve yöntem}

Araştırmanın şekli

Bu çalışma tanımlayıcı ve kesitsel araştırma tipindedir.

\section{Araştırmanın yapıldığı yer}

Araştırmanın uygulaması Cumhuriyet Üniversitesi kampüsünde yapılmıştır.

\section{Araştırmanın evreni ve örneklemi}

Araştırmanın evrenini Cumhuriyet Üniversitesi kampüsünde 2017-2018 eğitim-öğretim döneminde sağlık bilimleri alanında öğrenim gören son sınıf (intörn) öğrencileri (788 kişi) oluşturmuştur. Araştırmanın örneklemine ise 2017-2018 eğitim-öğretim dönemi bahar yarıyılında sağlık bilimleri alanında öğrenim gören, araştırmaya katılmaya gönüllü son sınıf öğrencileri (Sağlık Bilimleri Fakültesi: Hemşirelik 222 kişi, Ebelik 71 kişi, Sağlık Yönetimi 95 kişi, Diş Hekimliği Fakültesi: 69 kişi, Tıp Fakültesi: 150 kişi, Eczacılık Fakültesi: 17 kişi) olan 624 kişi alınmıştır. Bölümlerde öğrenim gören öğrenci sayılarına göre ağırlıklandırma yapılarak randomize şekilde örneklem seçim işlemi gerçekleştirilmiştir. Örnekleme yöntemi olarak sistematik örnekleme yöntemi uygulanmıştır.

\section{Veri toplama araçları}

Araştırmanın verileri araştırmacılar tarafından literatür bilgisi doğrultusunda oluşturulan Öğrenci Tanılama Formu, “Hasta Güvenliği Kültürü Ölçeği (HGKÖ)” ve Hasta Güvenliği Tutum Ölçeği (HGTÖ) ile toplanmıştır.

\section{Tanılama formu}

Anket formunda yaş, cinsiyet, aile tipi, gelir durumu vb. sosyodemografik özellikler, hasta güvenliği açısından en sık yapılan tıbbi hatalar, tıbbi hatalardan hasta etkilenimi vb. ilişkin ilgili literatür doğrultusunda oluşturulan 18 soru yer almaktadır (2,4-9,11-14). Tanılama formunda öğrencilerden, hasta güvenliğine ilişkin en sık yaptıkları hatalardan sadece birini işaretlemeleri istenmiştir. Öte yandan 
ilaç uygulaması yapmayan bazı bölümlerin intörn öğrencileri ilaç hataları gibi sorulardan muaf tutulmuştur.

\section{Hasta Güvenliği Kültürü Ölçeği (HGKÖ)}

Hasta güvenliği kültürünün değerlendirilmesi için Türkmen ve ark. (2010) tarafından geliştirilen HGKÖ kullanılmıştır (17). Hemşirelik grubunda geçerlilik-güvenilirlik çalışması yapılmış olan bu ölçek 51 maddeden oluşmaktadır. HGKÖ; yönetim ve liderlik (17 madde), çalışan davranışı (14 madde), beklenmedik olay ve hata raporlama (5 madde), çalışanların eğitimi (7 madde) ve bakım ortamı (8 madde) olmak üzere beş alt boyuttan oluşmaktadır. HGKÖ, dörtlü likert tipi bir ölçme aracıdır. Hasta güvenliği uygulamalarının etkinliği, "1 Tamamen katılmıyorum", "2 Katılmıyorum", "3 Katılıyorum", "4 Tamamen katılıyorum" şeklinde "1"den "4"e kadar değişen puanların sonuçlarına dayanılarak değerlendirilmiştir. Ölçek puanının yorumlanmasında ise puan ortalamasının 4'e doğru yükselmesi olumlu hasta güvenliği kültürünü, 1'e doğru azalması ise olumsuz hasta güvenliği kültürünün varlığını göstermektedir. Türkmen ve ark. tarafından HGKÖ'nin toplam Cronbach's Alfa güvenirlik katsayısı 0,97, alt boyutlarının 0,83-0,92 arasında bulunmuştur. Bu çalışmada ise HGKÖ'nin Cronbach's Alfa katsayısı 0,979 olarak elde edilmiştir. Ölçeğin alt boyutlarının Cronbach's Alfa katsayılarl; yönetim ve liderlik için 0,946 , çalışanların eğitimi için 0,904 , beklenmedik olay ve hata raporlama için 0,814 , bakım ortamı için 0,904 , çalışan davranışı için 0,943 olarak elde edilmiştir.

\section{Hasta Güvenliği Tutum Ölçeği (HGTÖ)}

HGTÖ ilk defa Sexton ve ark. (2006) tarafından geliştirilmiş olup, Baykal ve ark. (2010) tarafından Türkçe'ye uyarlanmıştır (18). Ölçek; iş doyumu (11 madde), ekip çalışması (12 madde), güvenlik iklimi (5 madde), yönetim anlayışı (7 madde), stresi tanılama (5 madde) ve çalışma koşulları (6 madde) olmak üzere 6 alt boyut ve 46 maddeden oluşmaktadır. Beşli likert tipinde olan ölçekte maddeler "5 tamamen katılıyorum", "4 katılıyorum", "3 kısmen katılıyorum","2 katılmıyorum", "1 kesinlikle katılmıyorum" şeklinde puanlanmakta olup, ölçeğin bazı maddeleri $(21,36,37,38$, $39,40,41,42,43,45$. maddeler) negatif puanlanmaktadır. Ölçekteki maddelerin madde toplam puan korelasyon değerleri 0,35 ile 0,58 arasında değişmektedir. Ölçek toplamının Cronbach alfa değeri 0,93 ve alt boyut Cronbach alfa değerleri sırasıyla; iş doyumu için 0,85 , ekip çalışması için 0,86 , güvenlik iklimi için 0,83 , yönetim anlayışı için 0,77 , stresi tanılama için 0,74 , çalışma koşulları için 0,72 'dir. Bu çalışmada ise HGTÖ toplamının Cronbach's Alfa katsayısı 0,930 olarak elde edilmiştir. Alt boyutların Cronbach's Alfa katsayıları ise; iş doyumu için 0,936 , ekip çalışması için 0,908, güvenlik iklimi için 0,907, yönetim anlayışı için 0,910 , stresi tanımlama için 0,910 ve çalışma koşulları için 0,802 olarak elde edilmiştir. HGTÖ'den alınan toplam puan araştırmaya katılanların hasta güvenliğine ilişkin tutumlarını yansıtmaktadır. Ölçekten alınabilecek en düşük puan 46 , en yüksek puan ise 230 'dur. Puan arttıkça hasta güvenliğine ilişkin tutum olumlu yönde artmaktadır.

\section{Araştırmanın uygulanması ve etik boyut}

Araştırmaya başlamadan önce Cumhuriyet Üniversitesi Girişimsel Olmayan Klinik Araştırmalar Etik Kurulu'ndan yazııı izin (2018-02/65), ilgili fakültelerin dekanlıklarından ve araştırmaya katılmayı kabul eden öğrencilerden yazııı ve sözel onam alınmıştır. Veriler araştırmacılar tarafından yüz yüze görüşme tekniği kullanılarak anket formu yolu ile toplanmıştır. Anket formuna isim yazılmaması, verilerin sadece araştırma kapsamında kullanılacağı, gizliliğin sağlanacağı belirtilmiştir. Her bir anketin uygulama süresi yaklaşık 15 dakika sürmüş olup, tüm katılımcılardan eksiksiz form dönüşü sağlanmıştır. Tüm anket verileri, veri analizine dahil edilmiştir.

\section{Verilerin değerlendirilmesi}

Verilerin değerlendirilmesinde değişkenlerin normal dağılıma uygunluğu Kolmogorov-Smirnov testi ile incelenmiştir. Değişkenler normal dağılım göstermediği için grupların karşılaştırılmasında nonparametrik istatistiksel yöntemlerden Kruskal-Wallis $\mathrm{H}$ testi kullanılırken istatistik parametreleri Medyan (min-max) olarak ifade edilmiştir. Kategorik değişkenlerin istatistik parametreleri yüzde (\%) ve frekanslar (n) ile ifade edilmiştir. İstatistiksel anlamlılık 0,05 önem düzeyinde incelenmiş olup SPSS 23 versiyonu kullanılmıştır.

\section{Bulgular}

Bazı sosyo-demografik özellikler açısından bakıldığında öğrencilerin; yarısından fazlasının cinsiyetinin kız $(\% 62,5)$, gelir durumunun orta düzeyde $(\% 80,1)$, çekirdek aile yapısında $(\% 66)$ ve 3 kardeşe sahip $(\% 59,6)$ olduğu belirlenmiştir. Öğrencilerin; okul başarısının ortalamaya uygun $(\% 63,1)$, aile ilişkilerinin $(\% 80,4)$, arkadaşlık ilişkilerinin $(\% 78,8)$ ve genel sağlık durumunun $(\% 66,2)$ iyi olduğu, çoğunluğunun yurtta kaldığı $(\% 85,7)$ ve hasta güvenliği konusunda eğitim aldığı $(\% 69,2)$ ve hasta güvenliği konusunda kendisini yeterli gördüğü $(\% 66,7)$ saptanmıştır. Araştırma yer alan son sınıf öğrencilerinin; \%24'ü (150 kişi) tıp fakültesi, \%11,1'i (69 kişi) diş hekimliği fakültesi, \%35,6'sı (222 kişi) hemşirelik bölümü, \%11,4'ü (71 kişi) ebelik bölümü, \%15,2'si (95 kişi) sağlık yönetimi bölümü, $\% 2,7$ 'si (17 kişi) eczacılık fakültesindendir. 
Tablo 1. Intörn öğrencilerin hasta güvenliği açısından tıbbi hata durumlarının dağlımı

\begin{tabular}{|c|c|c|}
\hline Tıbbi Hata Durum & & $n(\%)$ \\
\hline Tıbbi Hatalar & $\begin{array}{l}\text { İlaç hataları (yanlış: yol, doz, hasta vb.) } \\
\text { Hastane enfeksiyonları (asepsi, antisepsiye dikkat etmeme) } \\
\text { Düşmeler (gerekli güvenlik önlemlerini almama) } \\
\text { Yetersiz izlenimden kaynaklı hatalar } \\
\text { İletişim eksikliğinden kaynaklı hatalar } \\
\text { Yanlış ya da uygun olmayan malzeme kullanımı ve cihazlara bağlı hatalar } \\
\text { Toplam }\end{array}$ & $\begin{aligned} 317 & (50,8) \\
51 & (8,2) \\
21 & (3,4) \\
45 & (7,2) \\
152 & (24,4) \\
38 & (6,1) \\
624 & (100)\end{aligned}$ \\
\hline İlaç Hataları & $\begin{array}{l}\text { Yanlış ilacın verilmesi } \\
\text { Yanlış hastaya verilmesi } \\
\text { İstemin okunaksız olması } \\
\text { Yanlış doz verilmesi } \\
\text { Yanlış yol ile verilmesi } \\
\text { Parenteral ilaç uygulamalarında aseptik tekniklere uymama } \\
\text { İstemde aynı ilacın tekrarı } \\
\text { İlacın yanlış hız ile verilmesi } \\
\text { Tekniğe uymama } \\
\text { İlacın verilmemesi } \\
\text { Yanlış zamanda verilmesi } \\
\text { İlacın kaydedilmemesi } \\
\text { Toplam }\end{array}$ & $\begin{array}{c}53(16,7) \\
8(2,5) \\
7(2,2) \\
47(14,8) \\
46(14,5) \\
2(0,6) \\
17(5,4) \\
41(12,9) \\
29(9,1) \\
5(1,6) \\
22(6,9) \\
40(12,6) \\
317(100)\end{array}$ \\
\hline Hasta Etkilenimi & $\begin{array}{l}\text { Etkilemedi/hastaya ulaşmadı } \\
\text { Tedaviyi geciktirdi } \\
\text { Yan etki ortaya çıktı } \\
\text { Hastanede yatış süresini uzattı } \\
\text { Olası yaralanmaya neden oldu } \\
\text { Toplam }\end{array}$ & $\begin{array}{l}245(39,3) \\
173(27,7) \\
102(16,3) \\
71(11,4) \\
33(5,3) \\
624(100)\end{array}$ \\
\hline
\end{tabular}

Hasta güvenliği açısından öğrencilerin en sık yaptığı tıbbi hataların başında ilaç hataları $(\% 50,8)$ ve iletişim sorunlarından kaynaklı hatalar $(\% 24,4)$ gelmektedir. Öğrencilerin yaptığı ilaç hatalarının başında ise yanlış ilacın verilmesi $(\% 16,7)$, ilacın yanlış dozda verilmesi $(\% 14,8)$, yanlış yol ile verilmesi $(\% 14,5)$, yanlış hızla verilmesi $(\% 12,9)$ gelmektedir. Yapılan bu tıbbi hatalardan hasta birey bazen etkilenmemiş $(\% 39,3)$, bazen de tedavinin gecikmesi $(\% 27,7)$ ve yan etki ortaya çıkması $(\% 16,3)$ şeklinde etkilenmiştir (Tablo 1).

İntörn öğrencilerin hasta güvenliğine ilişkin kültür $(2,88)$ ve tutum (160) puanları olumlu yönde orta düzeyin üzerindedir. Öğrenciler, hasta güvenliği tutum ölçeği alt boyutlarından olan stres tanılama ve çalışma koşullarına ilişkin daha olumsuz, çalışanların eğitimi alt boyutuna ilişkin daha olumlu tutum puanına sahiptir (Tablo 2).

Hasta güvenliği kültür ölçeği puanları açısından yapılan tıbbi hata türleri arasındaki farklııı istatistiksel olarak anlamlı bulunmuştur $(p<0,05)$. Yanlış ya da uygun olmayan malzeme kullanımı ve cihazlara bağlı hatalar gerçekleştirenler daha olumlu hasta güvenliği kültür ölçeği puana sahip iken; düşmelere bağlı hata ve ilaç hataları gerçekleştirenler daha olumsuz hasta güvenliği kültür ölçeği puana sahiptir (Tablo 3).
Tablo 2. Intörn öğrencilerin hasta güvenliği tutum ve kültür düzeylerinin dağılımı

\begin{tabular}{lc} 
Ölçek Puan Ortalamaları (n: 624) & Median (Min-Max) \\
\hline Hasta Güvenliği Tutum Öıçeği Toplam (HGT0̈) & $\mathbf{1 6 0}(\mathbf{8 1 , 0 0 - 1 9 3 , 0 0 )}$ \\
İş doyumu & $37(11,00-55,00)$ \\
Ekip çalışması & $45(18,00-56,00)$ \\
Güvenlik iklimi & $20(5,00-25,00)$ \\
Yönetim anlayışı & $25(7,00-35,00)$ \\
Stres tanılama & $13(5,00-25,00)$ \\
Çalışma koşulları & $18(7,00-29,00)$ \\
\hline Hasta Güvenliği Kültür Öıçeği Toplam (HGKÖ) & $\mathbf{2 , 8 8}(\mathbf{1 , 0 0 - 3 , 9 0 )}$ \\
Yönetim ve liderlik & $2,88(1,00-3,94)$ \\
Çalışanların eğitimi & $3,50(1,17-4,67)$ \\
Beklenmedik olay ve hata raporlama & $2,80(1,00-4,00)$ \\
Bakım ortamı & $2,88(1,00-4,00)$ \\
Çalışan davranışı & $2,86(1,00-4,00)$
\end{tabular}

Hasta güvenliği kültür ve tutum ölçek puanına göre ilaçta yapılan hata türleri arasında istatistiksel olarak anlamlı farklııı mevcuttur $(p<0,05)$. Ölçek puanları bakımından ilaçla yapılan hata türleri arasında en olumlu seyri yanlış hastaya ilaç verenler gerçekleştirirken, en olumsuz seyri yanlış ilacı verenler izlemiştir. Ölçek puanı ile yapılan tıbbi hatalardan hasta bireyin etkilenimi arasındaki farklılık istatistiksel olarak anlamlı bulunmuştur $(p<0,05)$. Buna göre en düşük ölçek puanı yan etki ortaya çıkanlarda gözlemlenmiştir. Hasta güvenliği eğitimi alan ve almayan 
öğrenciler arasında HGKÖ ölçek puanları açısından anlamlı derecede farklılık saptanmıştır $(p=0,002)$. Eğitim alan öğrenciler eğitim almayanlara göre daha yüksek kültür düzeyine sahiptir. Benzer şekilde hasta güvenliği konusunda kendini yeterli bulma durumu ile HGTÖ puanı arasındaki farklıılı istatistiksel olarak anlamlı bulunmuştur $(p=0,001)$. Hasta güvenliği konusunda kendisini yeterli bulan öğrenciler daha olumlu tutuma sahiptir. Öğrencilerin öğrenim gördükleri bölümlere göre HGTÖ puanları arasındaki farklılık istatistiksel olarak anlamlıdır $(p<0,05)$. Buna göre eczacılık ve tıp intörn öğrencileri arasında hasta güvenliğine ilişkin tutum diğer bölümlere göre daha olumsuzdur (Tablo 3).

\section{Tartışma}

Sağlık hizmetinin sunumunun her aşamasında hasta güvenliğinin sağlanması ve tıbbi hataların önlenmesi sağlık sisteminin öncelikleri arasında yer almaktadır (19). Hasta güvenliği konusunu sağlık mesleği mensuplarının eğitim programlarına etkin bir şekilde entegre etmek, bu önceliğin ilerletilmesi için şarttır (20). Bu doğrultuda çalışmamızda intörn öğrencilerin yarısından fazlasının hasta

Tablo 3. Öğrencilerin hasta güvenliği tutum ve kültürlerinin tıbbi hata durumlarına etkisi

\begin{tabular}{|c|c|c|}
\hline Yapılan Tıbbi Hata Durumlarına Göre Intörnlerin Puanları (n: 624) & $\begin{array}{c}\text { HGKÖ } \\
\text { Median (Min-Max) }\end{array}$ & $\begin{array}{c}\text { HGTÖ } \\
\text { Median (Min-Max) }\end{array}$ \\
\hline $\begin{array}{l}\text { Tıbbi Hatalar } \\
\text { İlaç hataları (yanlış: yol, doz, hasta vb.) } \\
\text { Hastane enfeksiyonları (asepsi, antisepsiye dikkat etmeme) } \\
\text { Düşmeler (gerekli güvenlik önlemlerini almama) } \\
\text { Yetersiz izlenimden kaynaklı hatalar } \\
\text { Iletişim eksikliğinden kaynaklı hatalar } \\
\text { Yanlıs ya da uygun olmayan malzeme kullanımı ve cihazlara bağlı hatalar }\end{array}$ & $\begin{array}{l}2,67(1,0-3,63) \\
2,86(1,0-3,80) \\
2,59(1,82-3,08) \\
2,75(1,59-3,65) \\
2,97(1,71-3,90) \\
3,00(2,25-3,55)\end{array}$ & $\begin{array}{l}160(81,00-193,00) \\
160(81,00-190,00) \\
170(123,00-176,00) \\
165(81,00-190,00) \\
154(86,00-193,00) \\
164(123,00-190,00)\end{array}$ \\
\hline $\mathrm{kW} / \mathrm{p}$ & $13,911 / 0,016^{*}$ & $7,329 / 0,197$ \\
\hline $\begin{array}{l}\text { Yapılan Ilaç Hatalarına Göre } \\
\text { İntörnlerin Puanları' }(\mathrm{n}: 317)\end{array}$ & $\begin{array}{c}\text { HGKÖ } \\
\text { Median (Min-Max) }\end{array}$ & $\begin{array}{c}\text { HGTÖ } \\
\text { Median (Min-Max) }\end{array}$ \\
\hline $\begin{array}{l}\text { Yanlış ilacın verilmesi } \\
\text { Yanlış hastaya verilmesi } \\
\text { İstemin okunaksız olması } \\
\text { Yanlış doz verilmesi } \\
\text { Yanlıs yol ile verilmesi } \\
\text { Parenteral ilaç uygulamasında asepsiye uymama } \\
\text { İstemde aynı ilacın tekrarı } \\
\text { Illacın yanlış hız ile verilmesi } \\
\text { Tekniğe uymama } \\
\text { İlacın verilmemesi } \\
\text { Yanlıs zamanda verilmesi } \\
\text { Illacın kaydedilmemesi }\end{array}$ & $\begin{array}{l}2,25(1,00-3,80) \\
3,50(1,41-3,51) \\
2,92(1,00-3,29) \\
2,41(1,37-3,51) \\
3,49(1,00-3,80) \\
2,80(2,80-2,80) \\
3,02(2,96-3,12) \\
3,27(1,43-3,57) \\
3,18(1,71-3,33) \\
2,18(1,84-2,18) \\
2,78(2,14-3,76) \\
2,77(1,96-3,78)\end{array}$ & $\begin{array}{l}111(101,00-174,00) \\
179(107,00-186,00) \\
165(143,00-189,00) \\
175(116,00-186,00) \\
133(86,00-190,00) \\
155(155,00-155,00) \\
133(120,00-175,00) \\
158(107,00-193,00) \\
149(81,00-189,00) \\
175(169,00-175,00) \\
158(102,00-175,00) \\
160(123,00-192,00)\end{array}$ \\
\hline $\mathrm{KW} / \mathrm{p}$ & $57,487 / 0,001^{*}$ & $58,020 / 0,001^{*}$ \\
\hline $\begin{array}{l}\text { Hasta Güvenliği Konusunda Eğitim Alma Durumuna Göre } \\
\text { İntörnlerin Puanları' (n: 624) }\end{array}$ & $\begin{array}{c}\text { HGKÖ } \\
\text { Median (Min-Max) }\end{array}$ & $\begin{array}{c}\text { HGTÖ } \\
\text { Median (Min-Max) }\end{array}$ \\
\hline $\begin{array}{l}\text { Eğitim alan } \\
\text { Eğitim almayan }\end{array}$ & $\begin{array}{l}2,92(1,00-3,90) \\
2,67(1,63-3,65)\end{array}$ & $\begin{array}{r}151(81,00-193,00) \\
160(111,00-190,00)\end{array}$ \\
\hline Mann-Whitney U/p & $34954,50 / 0,002^{*}$ & $41309,00 / 0,938$ \\
\hline $\begin{array}{l}\text { Hasta Güvenliği Konusunda Yeterli Olma Durumuna Göre } \\
\text { İntörnlerin Puanları (n: 624) }\end{array}$ & $\begin{array}{c}\text { HGKÖ } \\
\text { Median (Min-Max) }\end{array}$ & $\begin{array}{c}\text { HGTÖ } \\
\text { Median (Min-Max) }\end{array}$ \\
\hline $\begin{array}{l}\text { Yeterli } \\
\text { Yetersiz }\end{array}$ & $\begin{array}{l}2,88(1,00-3,90) \\
2,89(1,43-3,63)\end{array}$ & $\begin{array}{l}164(81,00-192,00) \\
143(96,00-193,00)\end{array}$ \\
\hline Mann-Whitney U/p & $41097,00 / 0,307$ & $32512,50 / 0,001^{*}$ \\
\hline Bölüm/Fakültea (n: 624) & $\begin{array}{c}\text { HGKÖ } \\
\text { Median (Min-Max) }\end{array}$ & $\begin{array}{c}\text { HGTÖ } \\
\text { Median (Min-Max) }\end{array}$ \\
\hline $\begin{array}{l}\text { Tıp fakültesi öğrencileri } \\
\text { Diş hekimliği ögrencileri } \\
\text { Eczacılık öğrencileri } \\
\text { Hemşirelik öğrencileri } \\
\text { Ebelik öğrencileri } \\
\text { Sağlık yönetimi öğrencileri }\end{array}$ & $\begin{array}{l}2,81(1,00-3,90) \\
2,96(1,00-3,65) \\
2,96(1,75-3,90) \\
2,87(1,00-3,90) \\
2,90(1,00-3,90) \\
2,96(1,37-3,76)\end{array}$ & $\begin{array}{r}144(81,00-193,00) \\
166(101,00-190,00) \\
136(107,00-193,00) \\
160(81,00-193,00) \\
163(96,00-193,00) \\
158(81,00-187,00)\end{array}$ \\
\hline KW/p & $6,416 / 0,268$ & $13,012 / 0,023^{*}$ \\
\hline
\end{tabular}

akruskal Wallis $\mathrm{H}$ testi. ${ }^{\circ}$ Mann-Whitney U test; $\alpha$ : 0,05 . *Farkllliklar istatistiksel olarak anlamll. KW, Kruskal Wallis $\mathrm{H}$ test statistics. 
güvenliği konusunda eğitim aldığı ve hasta güvenliği konusunda kendisini yeterli gördüğü belirlenmiştir. Karaca ve Aslan'ın (2014) yaptığı çalışmada \%70'in üzerinde hemşirelerin hasta güvenliği ile ilgili bir eğitim aldığı ve aldıkları eğitimi yeterli bulduğu, Lee ve ark.'nın (2016) çalışmasında ise öğrencilerin \%53-56,5'inin hasta güvenliği konusunda eğitim aldığı saptanmıştır (21). Bu çalışmaların aksine Nabilou ve ark.'nın (2015) yaptıkları çalışmada hasta güvenliği konusunda öğrencilerin $\% 40$ 'ından fazlası kendi bilgisini zayıf, \%20'si iyi olarak değerlendirmiş, yaklaşık \%80'i daha fazla eğitime ihtiyaç duyduğunu belirtmiştir (22). Çalışma bulguları bize sağlık bilimleri alanındaki öğrencilerin eğitim programlarında hasta güvenliği konusunda yarıdan fazlasının eğitim almalarına rağmen bu oranın istendik düzeyde olmadığını göstermektedir. Tıbbi hataların önlenebilmesi açısından hasta güvenliği konusunu öğrencilerin tamamının alması önemlidir.

Hastanelerde en çok yapılan tıbbi hata türlerinin başında; ilaç hataları, hastane enfeksiyonları, yatak yaraları, tedavide gecikme veya tedavi yapmama, tanı koymada gerçekleşen hatalar ve ameliyat komplikasyonları gelmektedir (6,23-25). Öğrenciler, hasta güvenliği denildiğinde; ilaç güvenliğinin sağlanması, hastane enfeksiyonlarının önlenmesi ve hasta düşmelerinin önlenmesi şeklinde özellikle 3 konu üzerinde durmaktadırlar (5). Yapılan bir çaIışmada eğitim süresince öğrencilerin \%89,6'sı tıbbi hata yapmadığını, \%25,7'si ise ark.'nın tıbbi hata yaptığını gördüğünü belirtmiştir (6). Uygulamalarda en sık tanık olunan tıbbi hatalar ilaç ve iletişim eksikliğinden kaynaklanan hatalardır (26). Bizim çalışmamızda da hasta güvenliği açısından öğrencilerin en sık yaptığı tıbbi hataların başında ilaç hataları ve iletişim sorunlarından kaynaklı hatalar ön plana çıkmıştır. Çalışmalara göre öğrenciler uygulamada bireyde mortalite ve morbidite riskini artırabilen tıbbi hata türlerini (ilaç hataları, hastane enfeksiyonları vb.) yapabilmektedirler. Bu durum kliniklerde öğrenci sayılarının fazlalığından, öğretim elemanı sayısının azlığından, ülkemizde mentörlük uygulamasının henüz uygulamada yerini alamamasından ve hasta güvenliği konusuna yeterli önemin verilmemesinden kaynaklanıyor olabilir.

Öğrenciler, ilaç uygulamasında "sekiz doğru" ilkesinden uzaklaşarak zaman zaman hasta güvenliğini tehlikeye atabilmektedirler (16). Çevik ve ark. (2015) çalışmalarında öğrencilerin; \%9,5'inin doğru ilaç, \%10,3'ünün doğru doz, $\% 8,7$ 'sinin doğru yol, \%12'sinin doğru teknik, \%9,5'inin doğru hasta ilkelerine uymadığını belirlemiştir. Ayık ve ark.'nın (2010) çalışmasında ise en fazla yapılan ilaç hatalarının; oral ilaç uygulama esnasında hasta ilacı içinceye kadar yanında beklememe $(\% 73,7)$, oral ilacı hastanın yanına bırakma $(\% 71,9)$ ve başka birinin hazırladığı ilacı hastaya uygulama $(\% 70,1)$ olduğu saptanmıştır (27). Çalışmamızda ise öğrencilerin yaptığı ilaç hatalarının başında; yanlış ilacın verilmesi, ilacın yanlış dozda verilmesi, yanlış yol ile verilmesi, yanlış hızla verilmesi gelmektedir. Yapılan bu tıbbi hatalardan hasta birey bazen etkilenmemiş, bazen de tedavinin gecikmesi, yan etki ortaya çıkması şeklinde etkilenmiştir. Yapılan bu ilaç hataları bireylerde bazen geri dönüşü olmayan sekellere neden olabilmektedir. Bu nedenle öğrencilerin ilaç uygulama ilkelerinden uzaklaşmadan doğru uygulamalar yapması önemlidir.

Hasta güvenliği tutum ve kültürü, tıbbi hataları azaltma ve hasta güvenliğini artırma çabalarında önemli bir faktördür. Hasta güvenliği tutumunu geliştiren ve hatalardan öğrenmeyi kolaylaştıran bilgi, beceri ve tutumlar klinik ve teorik eğitim ile kazanılabilir. Klinik uygulama, simülasyon temelli, e-öğrenme sistemi ile verilen eğitim öğrencilerin ve çalışan sağlık personelinin hasta güvenliği tutumunu ve kültürünü olumlu yönde etkilemektedir $(28,29)$. Çalışmamızda hasta güvenliği konusunda eğitim alan intörn öğrenciler daha yüksek kültür düzeyine, eğitim alıp hasta güvenliği konusunda kendisini yeterli bulan öğrenciler ise daha olumlu tutuma sahiptir. Öğrencilerin hasta güvenliğine ilişkin kültür ve tutumları olumlu yönde orta düzeyin üzerindedir. Bu durum öğrencilerin hasta güvenliğine yönelik teorik ve uygulama açısından desteklendiklerini ancak bu desteğin istendik düzeyde olmadığını göstermektedir. Hasta güvenliği kültürü, tutumu ve tıbbi hata durumları konularına eğitim sürecinde müfredatta yeterli olarak yer verilmesi önemli ve önceliklidir (16).

Sağlık çalışanlarının ve öğrencilerinin hasta güvenliği tutumunu en üst düzeye çıkarmak için klinik ortamdaki deneyimleri sırasında desteklenmeleri gereklidir (30). Yapılan bir çalışmada acil serviste çalışan hemşirelerin hasta güvenliği tutum ölçeği alt boyutlarından yönetim anlayışına yönelik tutumlarının olumsuz olduğu belirlenirken (31), çalışmamızda yer alan öğrencilerde ise stres tanılama ve çalışma koşullarına yönelik tutum daha olumsuzdur. Nabilou ve ark.'nın (2015) yaptıkları çalışmada hemşirelik ve ebelik öğrencilerinin hasta güvenliği tutumları tıp fakültesi öğrencilerine göre daha yüksek çıkarken, çalışmamızda da eczacılık ve tıp intörn öğrencileri arasında hasta güvenliğine ilişkin tutum diğer bölümlere göre daha olumsuzdur. Bu bağlamda öğrencilerin hasta güvenliğine yönelik tutumlarının daha da olumlu olabilmesi için stres tanılama ve çalışma koşulları açısından daha fazla desteklenmeleri gerekmektedir. Hasta güvenliğine ilişkin olumsuz tutumunun nedeni; tıp fakültesi öğrencilerinin öğrenci sayılarının fazlalığından, uygulamada bire 
bir eğitim yapılamamasından, eczacılık öğrencilerinin ise teorik ağırlıklı ve yetersiz destekli uygulamadan kaynaklanıyor olabilir.

Güvenlik kültürü, personel tarafından paylaşılan ve tıbbi hata riskini azaltan alışkanlık davranışlarıyla ilişkili inançlar, algılar ve değerlerdir $(30,31)$. Çalışmamızda düşmelere bağlı hata ve ilaç hataları gerçekleştirenler daha olumsuz hasta güvenliği kültür ölçeği puanına sahiptir. Hasta güvenliği kültür ve tutum ölçeği puanları bakımından ilaçla yapılan hata türleri arasında en olumlu seyri yanlış hastaya ilaç verenler gerçekleştirirken, puanlar açısından en olumsuz seyri yanlış ilacı verenler izlemiştir. İlaç ve düşmeler

\section{Kaynaklar}

1. Dursun $S$, Bayram N, Aytaç $S$. Hasta güvenliği kültürü üzerine bir uygulama. Sosyal Bilimler 2010;8:1-14. http://www.acarindex.com/ dosyalar/makale/acarindex-1423874619.pdf

2. Karaca A, Aslan H. Hemşirelik hizmetlerinde hasta güvenliği kültürünün değerlendirilmesine yönelik bir çalışma. Sağlık ve Hemşirelik Yönetim Derg 2014;1:9-18. [CrossRef]

3. Severinsson E, Haruna M, Rönnerhag M, Holm LA, Hansen SB, Berggren I. Evidence of linkages between patient safety and personcentred care in the maternity and obstetric context- an integrative review. Open J Nurs 2017;7:378-98. [CrossRef]

4. Şen S, Er S, Sevil Ü. Hasta güvenliği ve tıbbi hatalar. Uluslararası Sağlıkta Performans ve Kalite Kongresi Bildiri Kitabı (Sözel Bildiri). Antalya; 2009.

5. Yıldız D, Fidancı BE, Ünver V, Kılıç HS, Yava A, Tosun N. Views of senior nursing students on patient safety. Gülhane Tıp Derg 2013;55:269-75.

6. Mankan T, Bahçecioğlu Turan GB, Türkben Polat H. Hemşirelik ve ebelik öğrencilerinde malpraktis. Sağlık Bilimleri ve Meslekleri Derg 2017;4:98-104. [CrossRef]

7. Andermann A, Ginsburg L, Norton P, Arora N, Bates D, Wu A, Larizgoitia I; Patient Safety Research Training and Education Expert Working Group of WHO Patient Safety. Core competencies for patient safety research: A Cornerstone for Global Capacity Strengthening. BMJ Qual Saf 2011;20:96-101. [CrossRef]

8. Holdsworth MT, Fichtl RE, Behta M, Raisch DW, Mendez-Rico E, Adams $A$, et al. Incidence and impact of adverse drug events in pediatric inpatients. Arch Pediatr Adolesc Med 2003;157:60-5. [CrossRef]

9. Sullivan JE, Buchino JJ. Medication Errors in Pediatrics-The octopus evading defeat. J Surg Oncol 2004;88:182-8. [CrossRef]

10. Bianchi M, Bressan V, Cadorin L, Pagnucci N, Tolotti A, Valcarenghi $D$, et al. Patient safety competencies in undergraduate nursing students: A rapid evidence assessment. J Adv Nurs 2016;72:2966-79. [CrossRef]

11. Kim FJ, Donalisio Da Silva R, Gustafson D, Nogueira L, Harlin T, Paul DL. Current issues in patient safety in surgery: A review. Patient Saf Surg 2015;9:1-9. [CrossRef]

12. World Health Organization (WHO). Fact File, 10 Facts on Patient Safety 2019. https://www.who.int/features/factfiles/patient_safety/ en/

13. Gökdoğan F, Yorgun S. Sağlık hizmetlerinde hasta güvenliği ve hemşireler. Anadolu Hemşirelik ve Sağlık Bilimleri Derg 2010;13:539. https://dergipark.org.tr/tr/download/article-file/29520 gibi hayati önemi olan tıbbi hatalar, hasta güvenliği kültür ve tutumunun geliştirilmesi gerektiğini göstermektedir, bu ise ancak teorik ve pratik açıdan uygun ve yeterli destek ile sağlanabilir.

\section{Sonuç}

Öğrencilerin hasta güvenliği kültür ve tutumları istendik düzeyde değildir ve bu durum hata yapma sıklığını veya olasılığını artırmaktadır. Hasta güvenliği kültür ve tutumunu artırarak tıbbi hata durumunu en aza indirgemek için eğitim müfredatı içerisindeki eksiklikler giderilmeli ve uygulamada yeterli destek sağlanmalıdır.

14. Agency for Healthcare Research and Quality. AHRQ's patient safety initiative: building foundation, reducing risk, 2003. https:// archive.ahrq.gov/research/findings/final-reports/pscongrpt/ psini2.html

15. Sharif $F$, Masoumi $S$. A qualitative study of nursing student experiences of clinical practice. BMC Nurs 2005;4:6. [CrossRef]

16. Bodur S, Filiz E, Çimen A, Kapçı C. Ebelik ve hemşirelik son sınıf öğrencilerinin hasta güvenliği ve tıbbi hatalar konusundaki tutumu. Genel Tıp Derg 2012;22:37-42. http://www.geneltip.org/upload/ sayi/9/GTD-00005.pdf

17. Türkmen $E$, Baykal Ü, Seren Ş, Altuntaş $S$. Hasta güvenliği kültürü ölçeğinin geliştirilmesi. Anadolu Hemşirelik ve Sağlık Bilimleri Derg 2011;14:38-46. https://dergipark.org.tr/tr/download/ article-file/29544

18. Baykal Ü, Şahin NH, Altuntaş S. Hasta Güvenliği Tutum Ölçeği'nin Türkçe'ye uyarlanması. Hemşirelikte Eğitim ve Araştırma Derg 2010;7:39-45. https://www.journalagent.com/kuhead/pdfs/ KUHEAD_7_1_39_45.pdf

19. Vural F, Çiftçi S, Fil Ş, Aydın A, Vural B. Sağlık çalışanlarının hasta güvenliği iklimi algıları ve tıbbi hataların raporlanması. Acıbadem Üniversitesi Sağlık Bilimleri Derg 2014;5:152-7. http://acibadem. dergisi.org/uploads/pdf/pdf_AUD_246.pdf

20. Doyle P, Vandenkerkhof EG, Edge DS, Ginsburg L, Goldstein DH. Self-Reported patient safety competence among Canadian medical students and postgraduate trainees: A cross-sectional survey. BMJ Qual Saf 2015;24:135-41. [CrossRef]

21. Lee NJ, Jang H, Park SY. Patient safety education and baccalaureate nursing students' patient safety competency: A cross-sectional study. Nurs Health Sci 2016;18:163-71. [CrossRef]

22. Nabilou B, Feizi A, Seyedin H. Patient safety in medical education: Students' perceptions, knowledge and attitudes. PLOS ONE 2015;10:E0135610. [CrossRef]

23. Alemdar DK, Aktaş YY. Medical error types and causes made by nurses in Turkey. TAF Prev Med Bull 2013;12:307-14. [CrossRef]

24. Cebeci F, Karazeybek E, Sucu Dağ G. Öğrenci hemşirelerin hastane uygulamaları sırasında tanık oldukları tıbbi hata durumları. Gümüşhane Üniversitesi Sağlık Bilimleri Derg 2014;3:736-48. https://dergipark.org.tr/en/download/article-file/220139

25. Canatan H, Erdoğan A, Yılmaz S. Hastanelerde yapılan tıbbi hataların türleri ve nedenleri üzerine bir araştırma: İstanbul ilinde özel bir hastane ile ilgili anket çalışması ve konuya ilişkin çözüm önerileri. Sağlık Akademisyenleri Derg 2015;2:82-9. [CrossRef] 
26. Çevik AF, Demirci A, Güven Z. Hemşirelik öğrencilerinin klinik eğitim sırasında yaptıkları ilaç uygulama hataları ve tıbbi hata farkındalıkları. Acıbadem Üniversitesi Sağlık Bilimleri Derg 2015;6:152-9.

27. Ayık G, Özsoy SA, Çetinkaya A. Hemşirelik öğrencilerinin ilaç uygulama hataları. Florence Nightingale Hemşirelik Derg 2010;18:136-43.

28. Gaupp R, Körner M, Fabry G. Effects of a case-based interactive elearning course on knowledge and attitudes about patient safety: A quasi experimental study with third-year medical students. BMC Med Educ 2016;16:1-8. [CrossRef]
29. Escher C, Creutzfeldt J, Meurling L, Hedman L, Kjellin A, FelländerTsai L. Medical students' situational motivation to participate in simulation based team training is predicted by attitudes to patient safety. BMC Med Educ 2017;17. [CrossRef]

30. Henderson AJ, Forrester K, Heel A. The establishment of structures and processes for the safe and effective clinical placement of nursing students. Nurse Educ Pract 2006;6:275-80. [CrossRef]

31. Balık $H$, Kaya $H$. Acil servislerde çalışan hemşirelerin hasta güvenliğine ilişkin tutumları. İstanbul Üniversitesi Sağlık Bilimleri Enstitüsü Yüksek Lisans Tezi, İstanbul 2014. 